Proceedings

\title{
Problems Related to Oak Regeneration in Central-Europe: From Acorn Production to Wild Boar Rooting ${ }^{\dagger}$
}

\author{
Dávid Sütő ${ }^{1,2, *}$, Sándor Siffer ${ }^{3}$, János Farkas ${ }^{1}$ and Krisztián Katona ${ }^{2}$ \\ 1 Department of Systematic Zoology and Ecology, Eötvös Loránd University, Pázmány Péter Sétány 1/C, \\ 1117 Budapest, Hungary; siffer.sandor@gmail.com \\ 2 Department of Wildlife Biology and Management, Institute for Wildlife Management and Nature \\ Conservation, Hungarian University of Agriculture and Life Sciences, Páter Károly Street 1., 2100 Gödöllö, \\ Hungary; katona.krisztian@uni-mate.hu \\ 3 Forestry Corporation of Bálint-hegy, Kossuth utca 9., Zánka 8251, Hungary; siffer.sandor@gmail.com \\ * Correspondence: sutod7@gmail.com \\ † Presented at the 1st International Electronic Conference on Biological Diversity, Ecology and Evolution, 15- \\ 31 March 2021; Available online: https://bdee2021.sciforum.net/.
}

Citation: Sütő, D.; Siffer, S.; Farkas,

J.; Katona, K. Problems Related to

Oak Regeneration in

Central-Europe: From Acorn

Production to Wild Boar Rooting.

Proceedings 2021, 68, $\mathrm{x}$.

https://doi.org/10.3390/xxxxx

Published: date

Publisher's Note: MDPI stays neutral with regard to jurisdictional claims in published maps and institutional affiliations.

Copyright: (c) 2021 by the authors. Submitted for possible open access publication under the terms and conditions of the Creative Commons Attribution (CC BY) license (http://creativecommons.org/licenses /by/4.0/).
Keywords: Quercus spp., acorn; forest regeneration; Sus scrofa; masting; ungulate impact

Throughout the temperate zone on the Northern Hemisphere, oaks (Quercus spp.) are among the most important tree species, although their regeneration has become weak recently. Acorns mean the basis of this process, and they can be affected by many factors like seed production, germination and predation. Oaks typically show mast seeding which has crucial and far-reaching multitrophic effect. Generalists like wild boars (Sus scrofa) often respond strongly to these masting events. Acorns are one of the most important components in their diet, therefore they are also usually considered as one of the main obstacles in the oak regeneration. In our research we examined a forest stand from 2016 October to 2019 December. We found that in the first two years Turkey oaks (Quercus cerris) were masting, but later produced almost nothing. While the sessile oaks (Quercus petraea) showed a relatively low, but quite balanced yield throughout our study. In spite of this, the acorn densities of the two species were quite similar during the second acorn rich period (2017 October to 2018 April), which implies a strong seed predator effect. During the successive seedling rich periods (April to November) we found more freshly emerged Turkey oak individuals, although with a relatively low abundance. Rooting of the wild boars disturbed the area more intensively during the first two, masting acorn rich periods. Our results demonstrate a strong connection among these phenomena throughout oak regeneration and help to better understand the whole process.

Institutional Review Board Statement:

Informed Consent Statement:

Data Availability Statement: 